\title{
Mechanical Characterization and Corrosion Behavior of Protective TiC/Amorphous C Nanocomposite Coating as Surface Thin Film
}

\author{
Nikolett Oláh $^{1 *}$, Mónika Furkó ${ }^{1}$, Zoltán May ${ }^{2}$, Attila Sulyok ${ }^{1}$ and Katalin Balázsi ${ }^{1}$ \\ ${ }^{1}$ Thin Film Physics Department, Institute for Technical Physics and Materials Science, Centre for Energy Research, \\ Hungarian Academy of Sciences, Konkoly-Thege M. str. 29-33, 1121 Budapest, Hungary \\ ${ }^{2}$ Plasma Chemistry Research Group, Institute of Materials and Environmental Chemistry, Research Centre for Natural Sciences, \\ Hungarian Academy of Sciences, Magyar tudósok körútja 2, 1117 Budapest, Hungary
}

Received: 09 May 2017; accepted: 28 August 2017

\begin{abstract}
The aim of this article is to study the influence of $\mathrm{TiC} / \mathrm{a}: \mathrm{C}$ protective thin film on the corrosion and mechanical properties of sandblasted/polished Ti and TiAl6V4 substrates. The electrochemical corrosion behaviors of the samples were investigated in simulated body fluid (SBF) by potentiodynamic polarization and electrochemical impedance spectroscopy (EIS) techniques at $7.4 \mathrm{pH}$ and $37^{\circ} \mathrm{C}$. The metal ion release has been quantified by inductively coupled plasma optical emission spectroscopy (ICP-OES). The experimental results obtained from different electrochemical methods, ICP-OES, and scanning electron microscopy (SEM) showed that the TiC/a:C protective coating on sandblasted implant device improves the corrosion properties of the implant material and it is able to control the metal ion release. It was also shown that the hardness of the bare implant materials is improving by four orders of magnitude with the TiC/a:C nanocomposite coating beside a moderate elastic modulus value. The highest hardness $(H)$ of $\sim 28 \mathrm{GPa} \pm 3$ was observed in the case of the film prepared at $\sim 38$ at $\%$ Ti content. Overall, the TiC/a:C thin film has suitable electrochemical characteristics for further consideration and assessment as a protective coating.
\end{abstract}

Keywords: TiC/a:C protective coating, potentiodynamic polarization method, mechanical properties, simulated body fluid, ICP-OES.

\section{Introduction}

Titanium (Ti) and its alloys, such as TiAl6V4, are known to be among the best biocompatible and the most commonly used metallic implant materials due to their excellent properties [1-4]. In spite of this fact, further materials and protective coatings are developed for long life implantation in human body by a multitude of researchers due to the continual growth of the world population, with their increasing age, the development of medical science, and the increase in traffic accidents, to prevent any kind of tissue inflammation and in order to avoid the removal of the implants [5-7]. Nevertheless, most of the common alloys that are used as implant materials contain vanadium (V), aluminum ( $\mathrm{Al}$ ), cobalt $(\mathrm{Co})$, copper $(\mathrm{Cu})$, chromium $(\mathrm{Cr})$, nickel $(\mathrm{Ni})$, and other toxic elements surrounded by corrosive media produced by biological systems $[5,8]$. Due to this corrosive media, these types of metal ions will be released in the body and cause tissue inflammation while the Ti can induce the release of potentially osteolytic cytokines involved in implant loosening [9-11].

The ideal biomaterial should be non-toxic, inert, and chemically stable while it should possess excellent biocompatibility and corrosion resistance. Numerous methods are available for the development of suitable implant materials. Each has known advantages and disadvantages. One solution can be producing more biocompatible - Al- and V-free - $\beta$-type Ti alloys containing non-toxic elements such as niobium $(\mathrm{Nb})$, molybdenum $(\mathrm{Mo})$, tantalum (Ta), manganese (Mn), and zirconium (Zr) with similar to bone Young's modulus value $(10-30 \mathrm{GPa})$ [12-15]. In addition to the excellent Young's modulus value, a further advantage of the $\beta$-type $\mathrm{Ti}$ alloys is that an especially inert oxide layer $\left(\mathrm{TiO}_{2}\right)$ consisting of a dense rutile structure forms on them [16]. This $\mathrm{TiO}_{2}$ passive film spontaneously forms on the TiAl6V4 alloy and $\mathrm{Ti}$ substrates as well and make them chemically stable materials [17]. Nevertheless, the most important disadvantage of

\footnotetext{
* Author for correspondence: olah.nikolett@energia.mta.hu
}

the mentioned elements $(\mathrm{Nb}, \mathrm{Ta}$, etc.) is the increased cost of producing implant materials.

The other solution could be the passivation of the implant material's surfaces with different protective coatings such as the mentioned $\mathrm{TiO}_{2}$ film or a titanium carbide (TiC)/amorphous carbon $(\mathrm{a}: \mathrm{C})$ protective coating. This passivation effect means that these surface coatings can control the metal ion release and increase the corrosion resistance [18-20]. Both TiC/a:C coating and rutile-type $\mathrm{TiO}_{2}$ passive film provide a barrier between the bio-environment and the different substrates [21, 22]. Thus, the probability of tissue inflammation is reduced and removal of the implants can be avoided.

$\mathrm{TiO}_{2}$ film alone has some disadvantages, such as low hardness, and it can be easily destroyed under harsh conditions, such as chloric environment, which ultimately lead to release of $\mathrm{Ni}, \mathrm{Al}, \mathrm{V}$, and the different toxic ions from the implant materials [13, 23, 24]. Moreover, various forms of oxide are able to form on the different Ti-based implants, such as $\mathrm{V}_{2} \mathrm{O}_{5}$ on the TiAl6V4 alloy, which dissolves and results lower corrosion resistance compared to the mentioned stable $\mathrm{TiO}_{2}$ layer on the other Ti implants and their alloys [25]. To overcome the abovementioned problem, the TiC/a:C thin film would be used as a substitute of $\mathrm{TiO}_{2}$ film. The reason to use $\mathrm{TiC} / \mathrm{a}$ :C nanocomposite thin film is because it is more stable under a variety of harsh conditions, it has good mechanical properties and biocompatibility, and it has superior corrosion resistance [26-28].

\section{Experimental}

2.1. Materials. The commercial sandblasted (s.b.) TiAl6V4 (ISO5832-3) with a diameter of $20 \mathrm{~mm}$ and thickness of $2 \mathrm{~mm}$, polished TiAl6V4 (ISO5832-3), and commercially pure (CP) Ti (ISO5832-2) with diameter of $35 \mathrm{~mm}$ and thickness of $2 \mathrm{~mm}$ substrates were purchased from Protetim Ltd. The TiAl6V4 bare material was roughened using a sandblasting procedure on one side of the wafer with corundum $\left(\mathrm{Al}_{2} \mathrm{O}_{3}\right)$ having a particle size of $60 \mu \mathrm{m}$ for better adhesion between the $\mathrm{TiC} / \mathrm{a}: \mathrm{C}$ protective 
coating and the substrate. The substrates were used in uncoated (bare) and by TiC/a:C thin film coated forms.

2.2. DC magnetron sputtering of thin films. TiC/a:C nanocomposite coatings were sputtered simultaneously from two targets (C and $\mathrm{Ti}$ ) by direct current (DC) magnetron sputtering without substrate heating occurred to improve the corrosion properties of the known implant materials. The reason is because the DC magnetron sputtering system has some advantage such as the chemical composition is easily changeable, fabricating largescale films is easy, hazardous gases or chemical precursors are not used, and it is inexpensive and more environmentally friendly [29-33].

One of the Ti and one of the TiAl6V4 substrates were ultrasonically cleaned for $10 \mathrm{~min}$ in ethanol and distilled water, and after that, their surfaces were purified by plasma cleaner before being put into the sputtering chamber. The 3 other substrates - one of the Ti, one of the TiAl6V4, and a sandblasted TiAl6V4 - were also ultrasonically cleaned for $10 \mathrm{~min}$ in ethanol and distilled water, and then, the substrates are rinsed and dried with nitrogen gas. After this procedure, the plasma cleaned Ti and TiAl6V4 and also the sandblasted TiAl6V4 wafers were mounted in the deposition chamber on a rotating substrate holder. The substrates were rotated with a speed of $20 \mathrm{rpm}$ during film growth. The Ti and $\mathrm{C}$ targets were pre-sputtered by argon (Ar) plasma for $10 \mathrm{~min}$ to clean them and remove any possible oxide layer prior to the deposition. The applied gas pressure and the power of the $\mathrm{C}$ source $(99.999 \%$, Kurt and Lesker) were kept constant at $2.5 \times 10^{-3}$ mbar and $150 \mathrm{~W}$, respectively, while the input power applied on the Ti source (99.995\%, Kurt and Lesker) was 40 and $50 \mathrm{~W}$. The sample-target distance was $\sim 70 \mathrm{~mm}$, and the Ar was used as the sputter gas.

2.3. Compositions and morphologies. X-ray photoelectron spectroscopy (XPS) and scanning electron microscopy (SEM) were used to study and compare the chemical compositions and morphologies of the deposited $\mathrm{TiC} / \mathrm{a}: \mathrm{C}$ protective thin films. XPS has been used to evaluate the chemical composition of the $\mathrm{TiC} / \mathrm{a}: \mathrm{C}$ nanocomposite coatings using an $\mathrm{Al}$ anode similarly to our previous experiments [27, 34, 35] containing the detailed description of this measurement. The XPS signal was collected from a macroscopic $5 \times 5 \mathrm{~mm}$ area. The measured composition is an average over depth determined by the inelastic mean free paths of electrons $(2.5 \mathrm{~nm})$. SEM measurements of the films before and after electrochemical stability tests were performed on SEM-LEO $1540 \mathrm{XB}$ microscope operated at 2 or $5 \mathrm{keV}$.

2.4. Measurement of mechanical properties. The mechanical characteristics of the samples were investigated by nanoindentation. The nanohardness $(H)$ and elastic modulus $(E)$ of the nanocomposite coatings were measured by a Nanoindenter Agilent G200 (USA) device with a Berkovich diamond indenter at room temperature. Clear areas were selected for indentation, and $4 \times 4$ indents were performed on TiC/a:C coated $\mathrm{Ti}$ and TiAl6V4 alloy. For comparison, measurements were conducted with bare $\mathrm{Ti}$ and TiAl6V4 reference samples as well. The indentation depth did not exceed $10 \%$ of the coating thickness $(\sim 700 \mathrm{~nm})$. The hardness and the indentation modulus values were automatically calculated according to the measuring standards based on the work of Oliver and Pharr [36], and visibly aberrant data were neglected from the averaging.

2.5. Electrochemical studies. Corrosion behavior of coated and uncoated samples can be studied either in vivo or in vitro using artificial physiological fluid wherein the conditions ( $\mathrm{pH} \sim 7.4$ and $37^{\circ} \mathrm{C}$ ) are similar to the environment of the human body. The simulated body fluid (SBF) is an example of an artificial solution, which should contain similar inorganic ions $\left(\mathrm{Ca}^{2+}, \mathrm{Mg}^{2+}, \mathrm{K}^{+} \mathrm{Na}^{+}, \mathrm{HPO}_{4}^{2-}, \mathrm{Cl}^{-}\right)$in similar concentrations to those of the human blood plasma to evaluate the in vitro ion release from implant materials [37].
Among the commonly used techniques, corrosion studies on the fabricated coatings were made in the SBF solution using the potentiodynamic polarization and the electrochemical impedance spectroscopy (EIS) techniques. The potentiodynamic and EIS measurements were carried out with Zahner IM6e electrochemical potentiostat/galvanostat (Zahner, Germany).

The electrochemical potentiodynamic polarization tests were performed in a standard three-electrode cell at a potential scanning rate of $0.5 \mathrm{mV} / \mathrm{s}$, and the atmosphere was open to air. The working electrodes were the metallic implant disks TiAl6V4 (ISO5832-3), Ti (ISO5832-2) with $3 \mathrm{~cm}^{2}$ active surface area, and the sandblasted TiAl6V4 (ISO5832-3) with $1.37 \mathrm{~cm}^{2}$ active surface area with and without $\mathrm{TiC} / \mathrm{a}: \mathrm{C}$ coating while the electrolyte was $100 \mathrm{~cm}^{3}$ for all tested samples. Platinum net and saturated calomel electrode (SCE) were used as counter electrode and reference electrode, respectively. The SBF serving as an electrolyte was prepared using the reagents listed in Table 1, just like in the work of Wang et al. [7], Barranco et al. [38], and Cheng et al. [39]. The tests were started after a steady open-circuit potential was attained (not more than $\pm 5 \mathrm{mV}$ drift in $5 \mathrm{~min}$ ).

EIS is a very useful and nondestructive technique for studying the corrosion behavior and protective stability of coated or uncoated surgical implant materials $[9,40]$, so these measurements were carried out at open circuit potential of the working electrode in SBF by applying a $10 \mathrm{mV}$ AC sine wave perturbation. During the EIS measurements, the frequency span was changed from $100 \mathrm{kHz}$ (initial frequency) down to $10 \mathrm{mHz}$ (final frequency). The impedance spectra were analyzed using electrical equivalent circuit (EEC) models (see later in Section 3.3.2.), while the impedance data were fitted and analyzed using Zview2 software.

2.6. Ion release. The dissolution behavior of the $\mathrm{TiC} / \mathrm{a}: \mathrm{C}$ thin film coated and also the uncoated $\mathrm{Ti}$ and TiAl6V4 substrates were analyzed for measuring the metal ion release quantitatively. The concentrations of metal ions released into solution were determined in $\mathrm{mg} / \mathrm{L}$. The potential released metal ion concentrations ( $\mathrm{Ti}, \mathrm{Al}, \mathrm{V})$ and the other residual ion concentrations from the $\mathrm{SBF}(\mathrm{Ag}, \mathrm{Ca}, \mathrm{Cu}, \mathrm{Fe}, \mathrm{K}, \mathrm{Mg}, \mathrm{Mn}, \mathrm{Na}$, $\mathrm{Ni}, \mathrm{P}, \mathrm{S}, \mathrm{Si}, \mathrm{Sr}$, and $\mathrm{Zn}$ ) were quantified by a simultaneous Spectro Genesis Inductively Coupled Plasma Optical Emission Spectrometer (ICP-OES) [41, 42] equipped with axial plasma viewing and CCD detector system $(175-775 \mathrm{~nm})$ at the end of the experiment.

\section{Results and discussion}

3.1. Compositions and morphologies. XPS analysis was carried out on all films and compared with previous experiments in order to reveal their composition and their reproducibility. These results are summarized in Table 2 depending on the Ti target power ( 40 or $50 \mathrm{~W})$. There is a good correlation between the thin films prepared at $40 \mathrm{~W} \mathrm{P}_{\mathrm{Ti}}$ (4 different layers) and between the thin films deposited at $50 \mathrm{~W} \mathrm{P}_{\mathrm{Ti}}$ (3 different layers) within the margin of error. Thus, it was also observed that the

Table 1. Chemical composition of SBF

\begin{tabular}{lc}
\hline Reagent & $\begin{array}{c}\text { Amount } \\
(\mathrm{g} / \mathrm{L})\end{array}$ \\
\hline Sodium chloride & 7.996 \\
Sodium bicarbonate & 0.350 \\
Potassium chloride & 0.224 \\
Potassium phosphate dibasic trihydrate & 0.228 \\
Magnesium chloride hexahydrate & 0.305 \\
1 M Hydrochloric acid & $40 \mathrm{~mL}$ \\
Calcium chloride & 0.278 \\
Sodium sulfate & 0.071 \\
Tris(hydroxymethyl) aminomethane & 6.057 \\
pH & 7.4 \\
\hline
\end{tabular}


Table 2. Comparison of the concentration of components in the TiC/a:C thin films deposited under the same conditions depending on the different Ti target power ( $40 \mathrm{~W} \mathrm{P}_{\mathrm{Ti}}$ for 4 different layers and $50 \mathrm{~W} \mathrm{P}_{\mathrm{Ti}}$ for 3 different layers)

\begin{tabular}{|c|c|c|c|c|c|}
\hline Thin films & $\mathrm{P}_{\mathrm{Ti}}(\mathrm{W})$ & $\mathrm{Ti}($ at $\%)$ & Total amount of $\mathrm{C}(\mathrm{at} \%)$ & $\mathrm{O}(\mathrm{at} \%)$ & Ar (at $\%)$ \\
\hline $\mathrm{TiC} / \mathrm{a}: \mathrm{C}$ on $\mathrm{SiO}_{2} / \mathrm{Si}[34] \sim 400 \mathrm{~nm}$ & 40 & $33.4 \pm 3$ & $59.6 \pm 6$ & $3.9 \pm 1$ & $3.1 \pm 1$ \\
\hline $\mathrm{TiC} / \mathrm{a}: \mathrm{C}$ on $\mathrm{SiO}_{2} / \mathrm{Si}[35] \sim 150 \mathrm{~nm}$ & 40 & $37.7 \pm 4$ & $62.2 \pm 7$ & $1.4 \pm 1$ & $1.8 \pm 0.3$ \\
\hline TiC/a:C coated $\mathrm{Ti} \sim 700 \mathrm{~nm}$ & 40 & $38.8 \pm 4$ & $56.9 \pm 6$ & $3.3 \pm 0.6$ & $1 \pm 0.3$ \\
\hline $\mathrm{TiC} / \mathrm{a}: \mathrm{C}$ on $\mathrm{SiO}_{2} / \mathrm{Si}[34] \sim 400 \mathrm{~nm}$ & 50 & $39.7 \pm 4$ & $52.4 \pm 10$ & $4.1 \pm 1$ & $3.7 \pm 1$ \\
\hline $\mathrm{TiC} / \mathrm{a}: \mathrm{C}$ on $\mathrm{SiO}_{2} / \mathrm{Si}[35] \sim 150 \mathrm{~nm}$ & 50 & $43.4 \pm 4$ & $56.6 \pm 7$ & $7.1 \pm 1$ & $1.5 \pm 0.3$ \\
\hline TiC/a:C coated s.b. TiAl6V4 400 nm & 50 & $40.2 \pm 4$ & $43.2 \pm 8$ & $14.9 \pm 0.6$ & $1.6 \pm 0.3$ \\
\hline
\end{tabular}

elemental composition does not depend on the layer's thickness or the nature of the applied substrates.

The SEM images of the uncoated Ti $(a, b)$ and TiAl6V4 (c, d) substrates before $(a, c)$ and after $(b, d)$ the corrosion tests are shown in Figure 1a-d, while the further SEM micrographs pre-
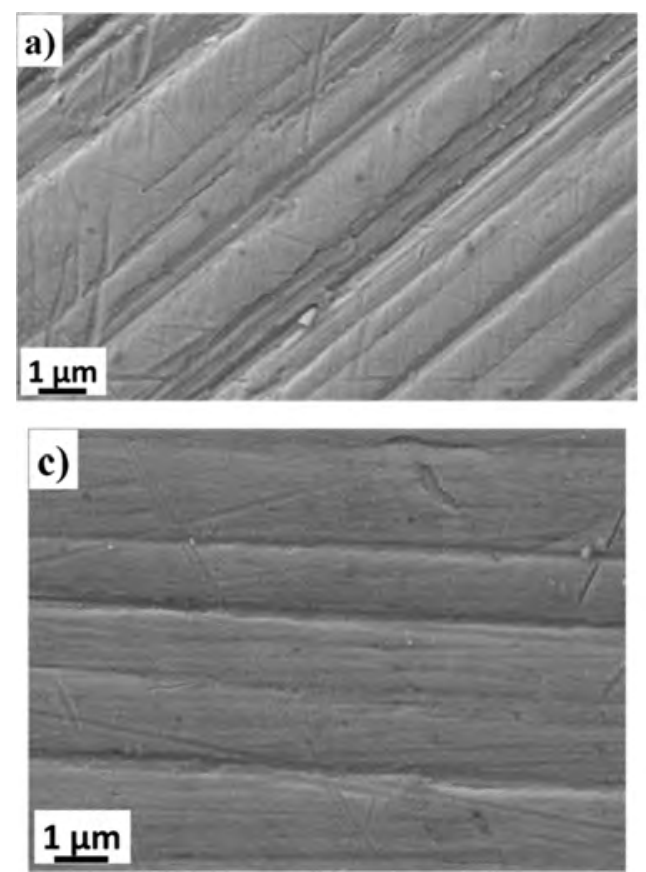

sented in Figures 2-4 show the changes of the surface morphologies of the TiC/a:C coated samples after the corrosion tests. The samples were immersed in the solution for 26 days. In the case of bare materials (Figure 1), TiC/a:C coated polished CP Ti (Figure 2), and TiAl6V4 wafers (Figure 3) with
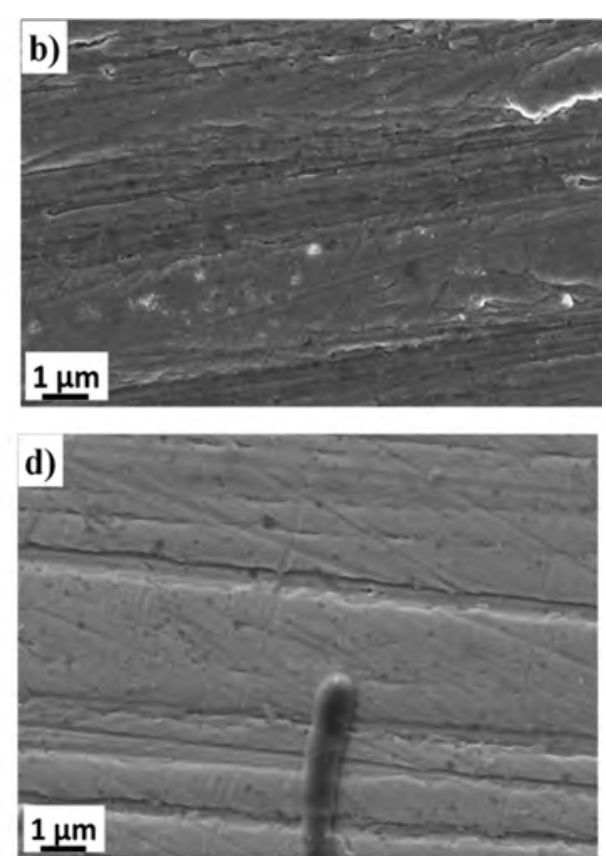

$1 \mu \mathrm{m}$

Figure 1. SEM images about the uncoated Ti $(a, b)$ and TiAl6V4 (c, d) substrates before $(a, c)$ and after $(b, d)$ the corrosion examinations tested in SBF
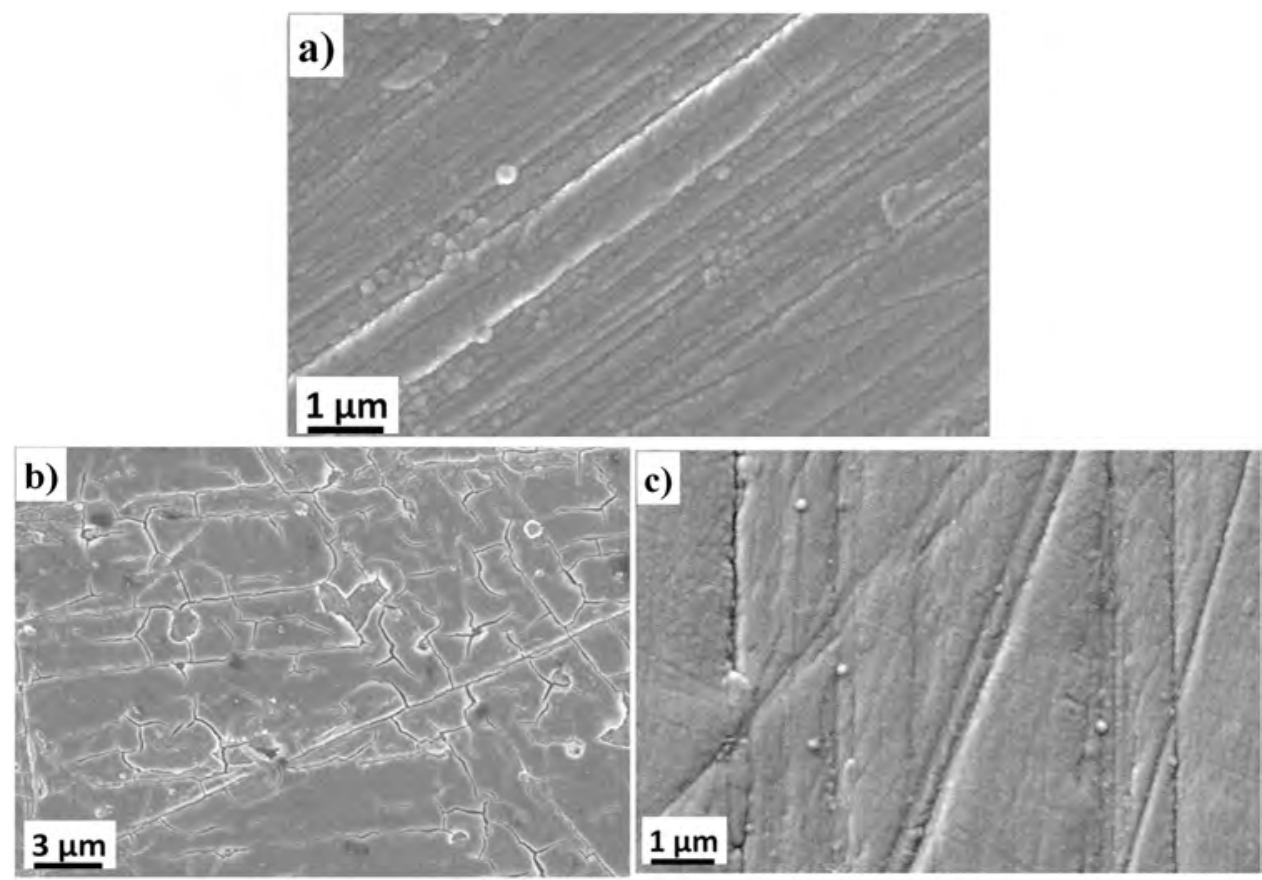

Figure 2. SEM images corrosion tests: a) TiC/a:C/Ti before corrosion tests, b) TiC/a:C coated $\mathrm{Ti}$ after tests in $\mathrm{SBF}$ (the electrodes were attached to this side of the sample), and c) $\mathrm{TiC} / \mathrm{a}: \mathrm{C} / \mathrm{Ti}$ after immersion in $\mathrm{SBF}$ 

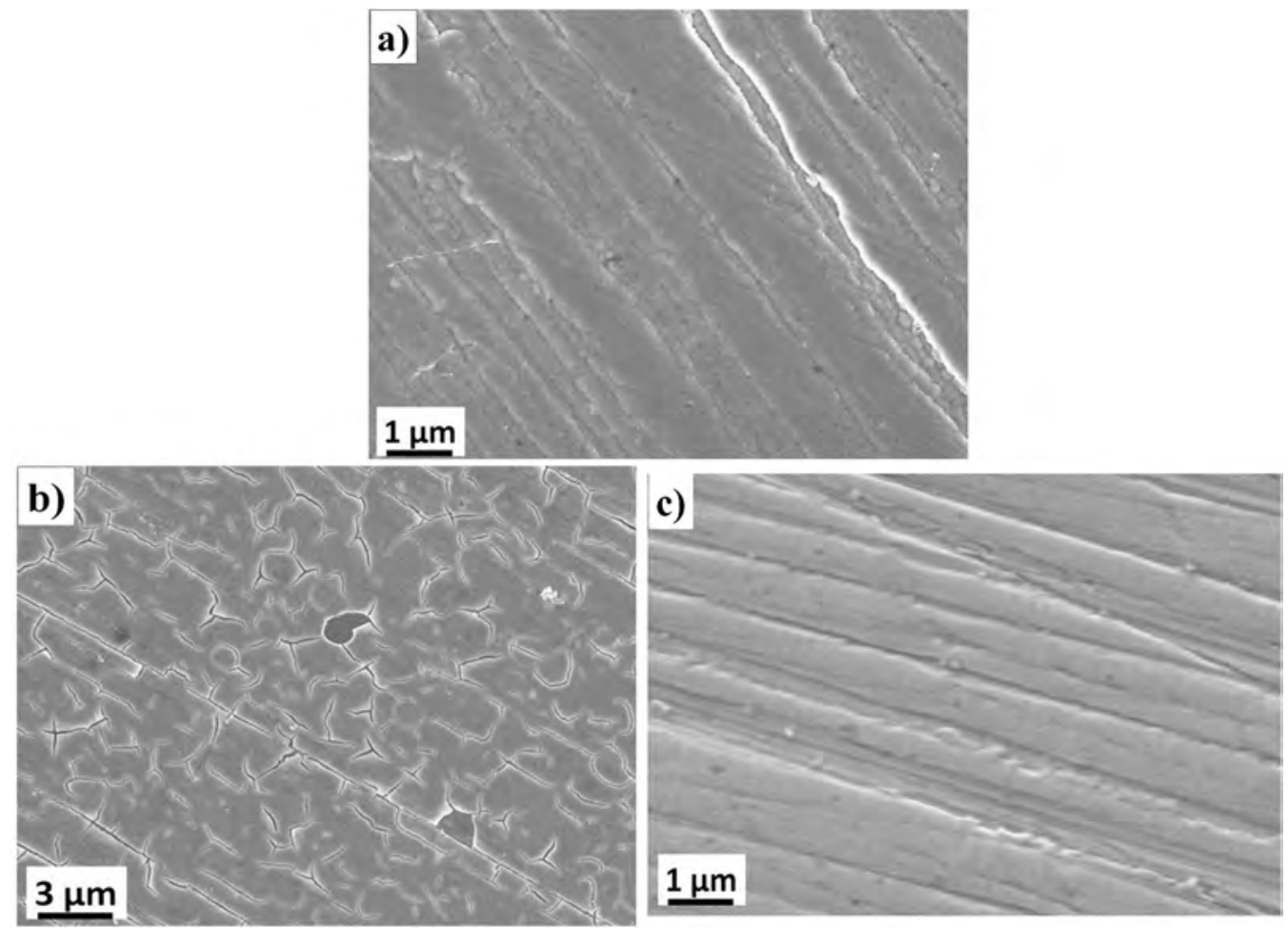

Figure 3. SEM images corrosion tests: a) TiC/a:C/TiAl6V4 before corrosion tests, b) TiC/a:C coated TiAl6V4 after tests in SBF (the electrodes were attached to this side of the sample), and c) TiC/a:C/TiAl6V4 after immersion in SBF

disk diameter of $35 \mathrm{~mm}$, the electrodes were attached to the left side of the samples. In the case of $\mathrm{TiC} / \mathrm{a}: \mathrm{C}$ coated s.b. TiAl6V4 (Figure 4) with disk diameter of $20 \mathrm{~mm}$, the electrodes were attached to whole of the sample. In the case of bare materials (Figure $1 \mathrm{~b}$ and $\mathrm{d}$ ) and TiC/a:C coated s.b. TiAl6V4 (Figure $4 \mathrm{~b}$ and $\mathrm{c}$ ), any special changes on their surfaces cannot be experienced after the electrochemical tests despite of the TiC/a:C coated polished substrates. The presented images (Figures $2 \mathrm{~b}$ and $3 \mathrm{~b}$ ) show the same influence for the degradation of the TiC/a: $\mathrm{C}$ coated polished Ti and TiAl6V4 alloy materials to which were exposed to the electrochemical tests. Their surface is corroded due to the electrochemical tests; however, the other part of the samples (Figures 2c and 3c), which is only soaked in the solution during 26 days, does not show special changes. The SEM analysis revealed TiC/a:C coating on polished $\mathrm{Ti}$ and TiAl6V4 with fewer defects (Figures $2 \mathrm{~b}$ and $3 \mathrm{~b}$ ) while the $\mathrm{TiC} / \mathrm{a}: \mathrm{C}$ coated s.b. TiAl6V4 (Figure 4b) surfaces without defects which refers to the
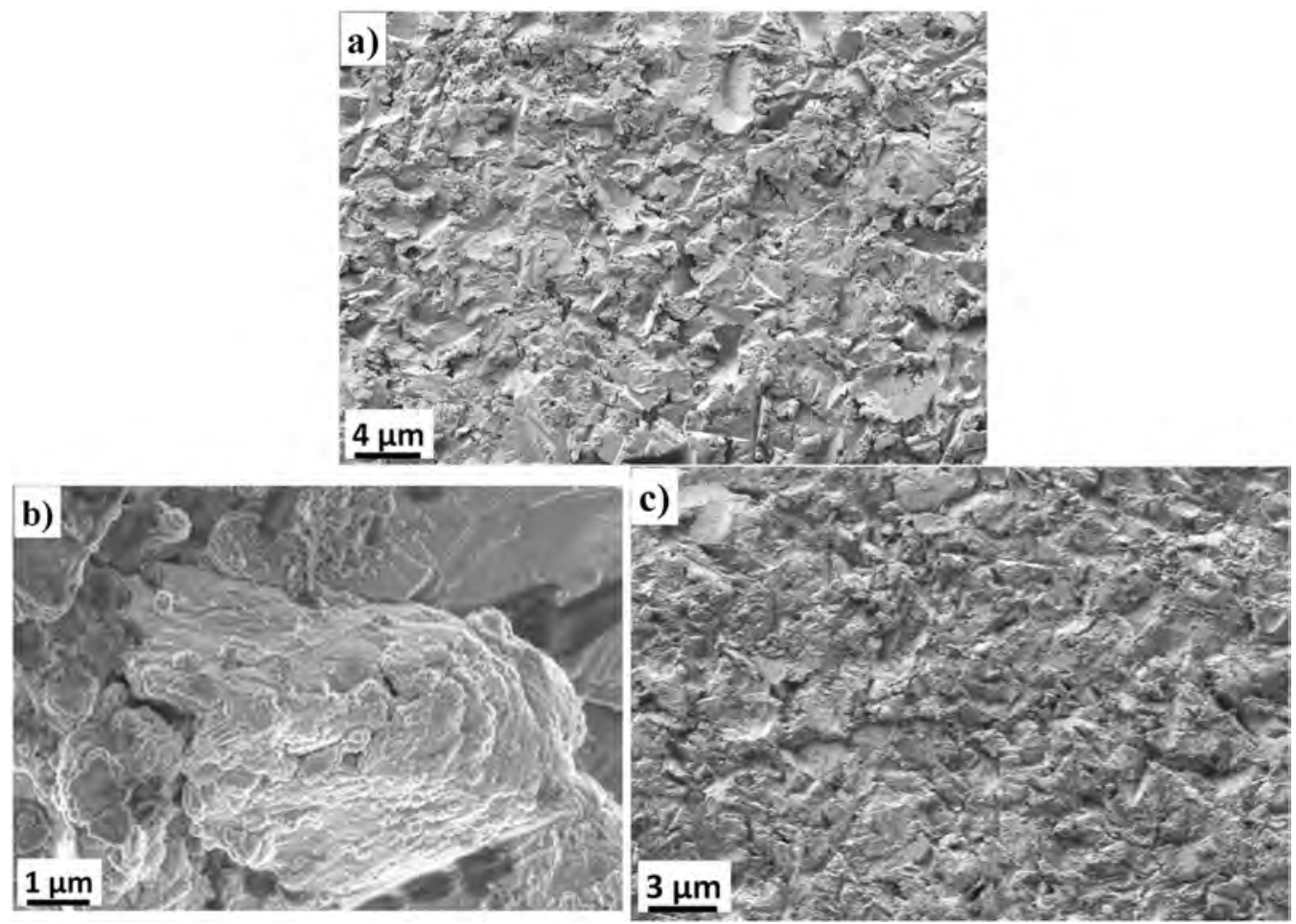

Figure 4. SEM images corrosion tests: a) TiC/a:C/s.b. TiAl6V4 before corrosion tests; b), c) TiC/a:C coated s.b. TiAl6V4 after tests in SBF (the electrodes were attached to whole of the sample) 
higher corrosion resistance of the TiC/a:C coated s.b. TiAl6V4 sample shown in Figure 4. Thus, based on the SEM analyses, the morphologically most suitable TiC/a:C thin film in terms of the corrosion properties is the TiC/a:C coated s.b. TiAl6V4 sample (Figure 4), which was deposited on roughened surface.

3.2. Mechanical properties. The $H(\mathrm{a})$ and $E(\mathrm{~b})$ values of the Ti substrate are compared to those of the TiC/a:C thin film containing $38.8 \pm 4$ at $\% \mathrm{Ti}$ and is demonstrated in Figure 5, while the $H(\mathrm{c})$ and $E(\mathrm{~d})$ values of the TiAl6V4 substrate are compared to those of the $\mathrm{TiC} / \mathrm{a}: \mathrm{C}$ thin film containing $39.9 \pm 4$ at $\% \mathrm{Ti}$ and is demonstrated in Figure 6. In both cases, the $H$ of the TiC/a: $\mathrm{C}$ thin films prepared at $40 \mathrm{~W}$ of $\mathrm{Ti}$ target power is by orders of magnitude better than that is of the bare substrates. It is $\sim 28 \mathrm{GPa} \pm 3$ in the case of TiC/a:C thin film on Ti substrate (Figure 5a), and it is $\sim 27 \mathrm{GPa} \pm 2$ in the case of TiC/a:C thin film on TiAl6V4 substrate (Figure 6a). These values are $3.5 \mathrm{GPa} \pm 0.2$ for bare $\mathrm{Ti}$ and $5 \mathrm{GPa} \pm 0.2$ for bare TiAl6V4 wafers. These are the most suitable composition in terms of the mechanical properties. However, in terms of the modulus of elasticity, the bare substrates have better values. It is $\sim 125 \mathrm{GPa} \pm 15$ in the case of bare Ti substrate (Figure $5 \mathrm{~b}$ ) and it is $\sim 130 \mathrm{GPa} \pm 10$ in the case of bare TiAl6V4 substrate (Figure $6 \mathrm{~b}$ ). These values are $280 \mathrm{GPa} \pm 40$ for $\mathrm{TiC} / \mathrm{a}: \mathrm{C}$ coated $\mathrm{Ti}$ and $270 \pm 20$ for TiC/a:C coated TiAl6V4 wafers.

\subsection{Electrochemical studies vs. ICP-OES}

3.3.1. Potentiodynamic polarization measurements. In order to compare the susceptibility to corrosion of the TiC/a:C coated substrates in relation to the bare alloy materials, potentiodynamic polarization curves were recorded (Figure 7). The
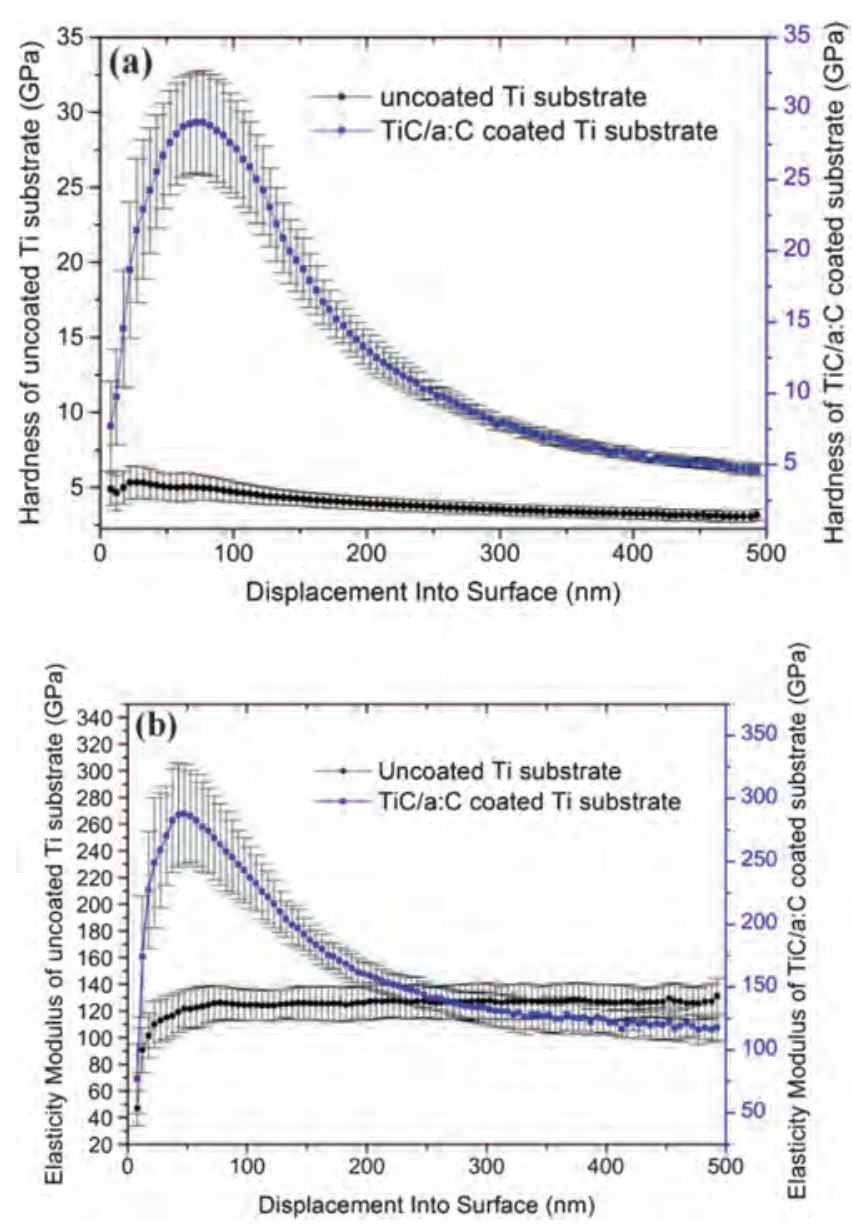

Figure 5. Comparison of the $H$ (a) and the $E$ (b) values of the uncoated and $\mathrm{TiC} / \mathrm{a}: \mathrm{C}$ coated $\mathrm{Ti}$ substrate
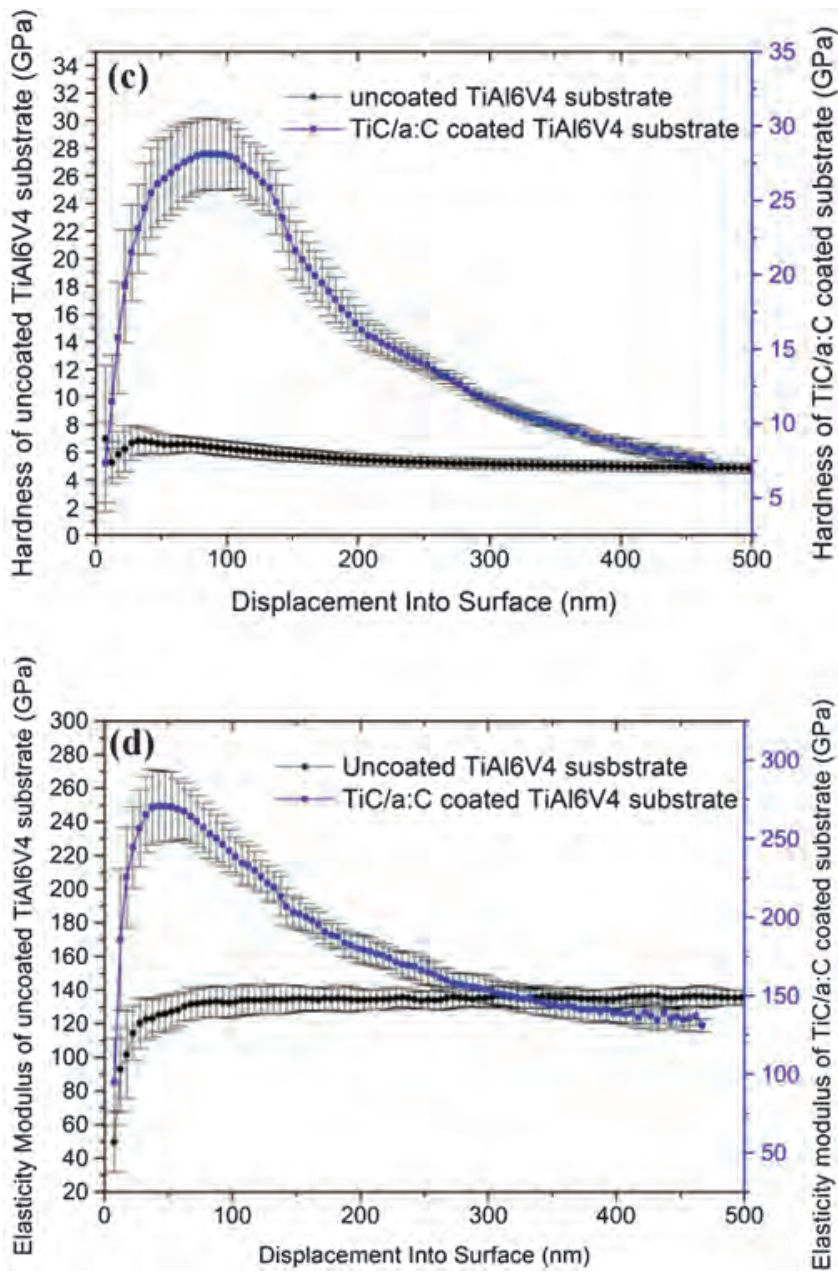

Figure 6. Comparison of the $H$ (c) and the $E$ (d) values of the uncoated and $\mathrm{TiC} / \mathrm{a}: \mathrm{C}$ coated TiAl6V4 substrate

anodic and cathodic polarization curves were obtained for each sample. The potentiodynamic curves were recorded during longterm immersion for several times. Corrosion current density $\left(j_{\text {corr. }}\right)$ and corrosion potentials of samples can be determined from the potentiodynamic polarization curves by Tafel extrapolation method. In our case, the intersection of corrosion potential and the linear extrapolated to the cathodic branches of curves will give the corrosion current density values.

As it is visible in Figure 7, the shapes of potentiodynamic curves of pure implant substrates (Ti: Figure 7a, TiAl6V4: Figure 7c) are similar. In these cases, the cathodic branches of curves show mainly kinetic controlled cathodic reactions while the anodic branches show diffusion-controlled anodic processes. The anodic branches have wide passive region from the open circuit potential to around $1.5 \mathrm{~V}$ vs. SCE. This can be explained by a protective passive oxide layer formation at anodic overpotentials. The passive current densities $\left(j_{\mathrm{p}}\right)$ values decrease with immersion time. At potentials higher than $1.5 \mathrm{~V}$, a slight increase in passive current can be observed which might be attributed to the damage of passive oxide layer [2]; however, repassivation occurred in all cases time point. In the case of $\mathrm{TiC} / \mathrm{a}: \mathrm{C}$ coated substrates, the recorded potentiodynamic curves show different shape (Figure 7b, d, and e). For these samples, a notable decrease in the anodic passive current occurs on the anodic branches of curves at around $-1 \mathrm{~V}$ vs. SCE following with large passive areas. The passive currents also decrease as time passes. The $j_{\mathrm{p}}$ values of $\mathrm{TiC} / \mathrm{a}: \mathrm{C}$ coated materials are higher by around one order of magnitude in all cases.

3.3.2. EIS measurements. Impedance spectra are presented in both complex impedance diagrams (Nyquist plot), Bode 

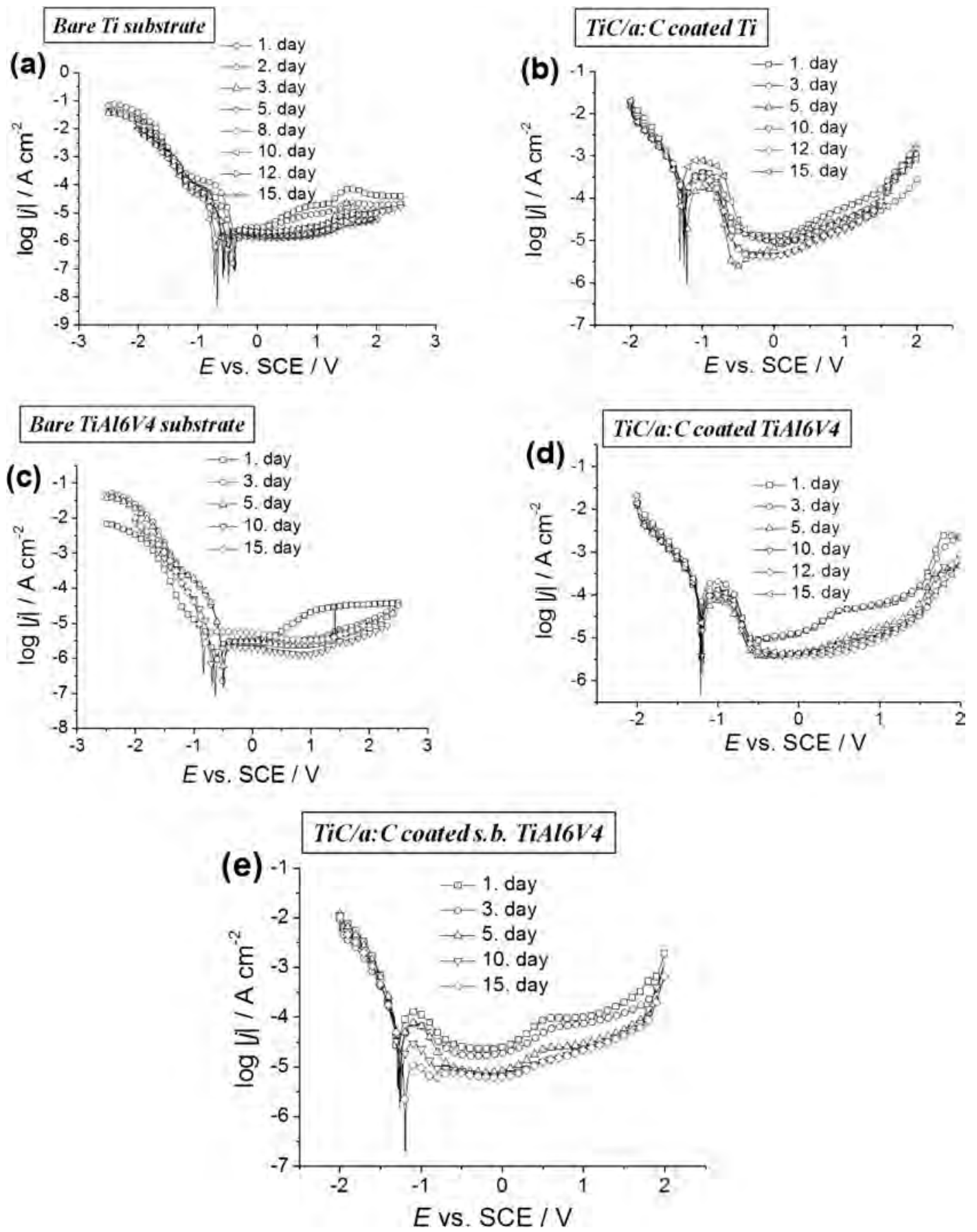

Figure 7. Potentiodynamic measurements on TiC/a:C coated and uncoated implant materials in $\mathrm{SBF}$ at $37{ }^{\circ} \mathrm{C}$. (a) $\mathrm{Ti}$ substrate, (b) TiC/a:C coated Ti, (c) TiAl6V4 substrate, (d) TiC/a:C coated TiAl6V4, and (e) TiC/a:C coated s.b.TiAl6V4

amplitude, and phase angle plots. In the Nyquist graph, the imaginary component of the impedance is plotted as a function of the real component, whereas the Bode representation shows the logarithm of the impedance modulus $|Z|$ and phase angle $\phi$ as a function of the logarithm of the frequency $(f)$. The investigated samples were initially immersed into solution and left at opencircuit for $30 \mathrm{~min}$ to stabilize the surface of specimen. A convenient way to evaluate the corrosion properties of the samples is to compare the diameters of the semicircles in Nyquist plot.

Figure 8 demonstrates the Nyquist and Bode plots of samples. It can be observed from Figure $8 \mathrm{a}$ and $\mathrm{c}$ that the complex planes of pure implant materials are all wide capacitive arc which is characteristic of capacitive behavior. This capacitive property is also proven by the phase angle values close to $80^{\circ}$ at low frequency range [4]. The shape of Bode plot of Ti and TiAl6V4 substrates are quite similar, they both show two distinctive phase maximums which can refer to two-time constants at high and middle frequency range. The total impedance values of $\mathrm{CP} \mathrm{Ti}$ slightly higher than that of TiAl6V4 alloy (Figure 8b and d). The Nyquist plots are similar capacitive arcs in the cases of TiC/a:C coated samples. However, in these cases, the arcs are smaller and bend over the real axis which can refer their lower corrosion resistance (Figure 8e and g), while the Nyquist plot of TiC/a:C coated s.b. TiAl6V4 is hardly changed with time, indicating its stable and continuous corrosion rate compared to the other samples.

The Bode plots of TiC/a:C coated substrates can be interpreted as three time-constant plots: one in middle frequency range (refer to phase angle maximum at around $10 \mathrm{~Hz}$ ) and two overlapping time constants (two merging phase angle maximum) in low frequency range. The maximum of phase angle is lower for TiC/a:C layers (they vary between $70^{\circ}$ and $75^{\circ}$ over time in all cases as in 
(a)

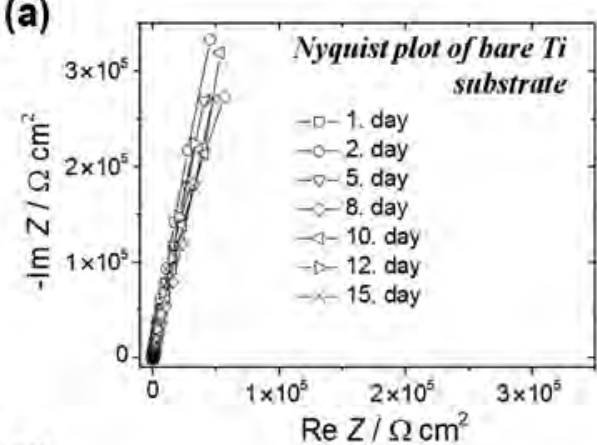

(c)

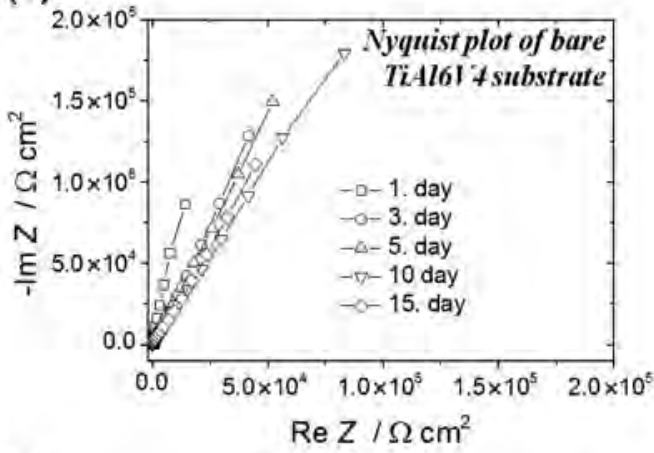

(e)

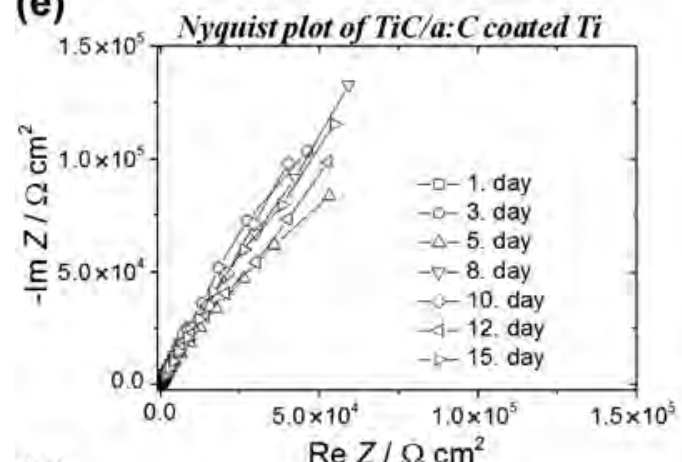

(g)

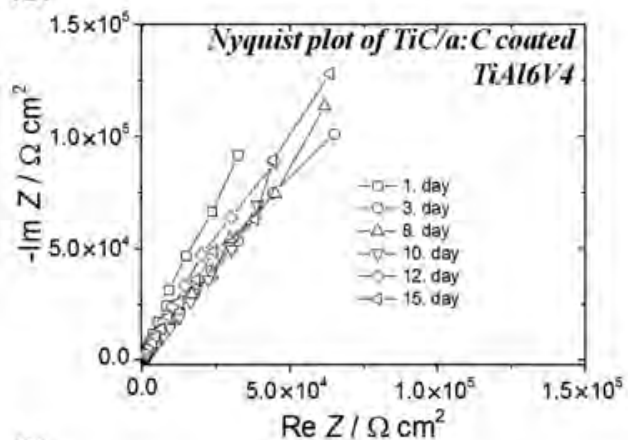

(i)

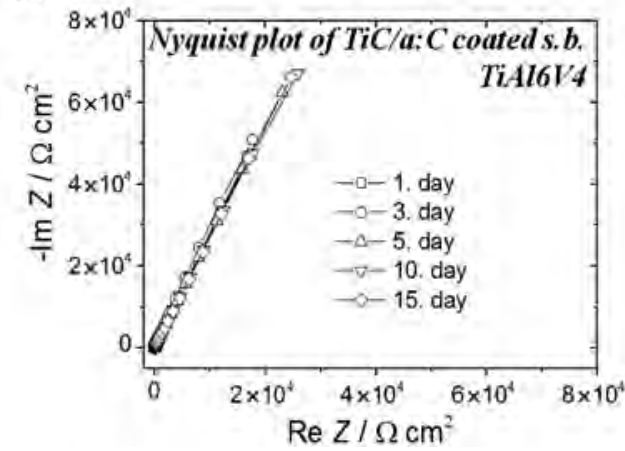

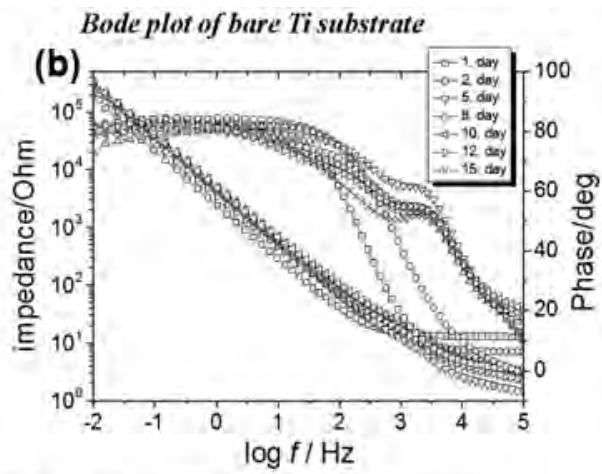

(d) Bode plot of bare TiAl6/4 substrate

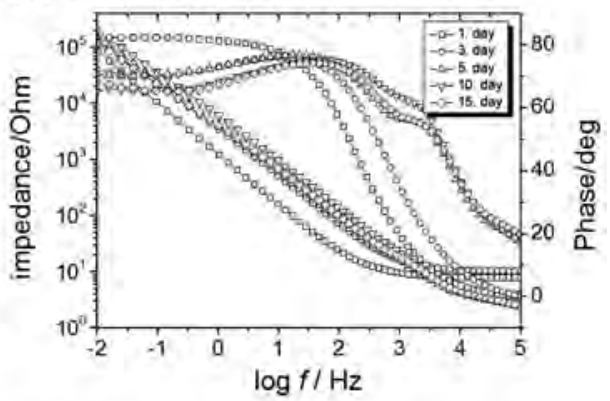

(f) Bode plot of TiC/a:C coated Ti

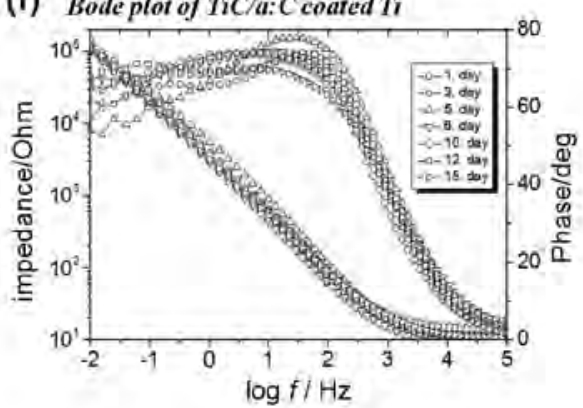

(h) Bode plot of TiC/a:C coated THAl6K4

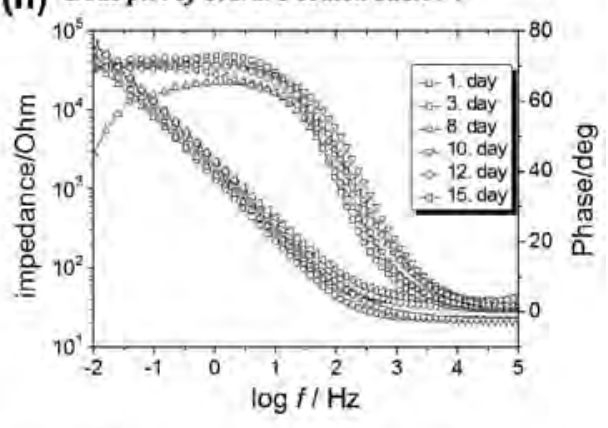

(j) Bode plot of TiC/a:C coated s.b. TiAl6V/4

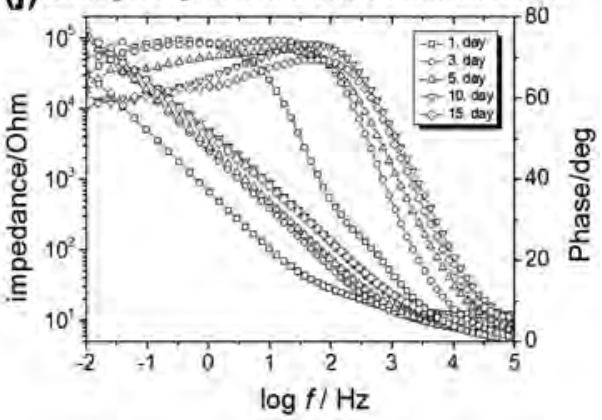

Figure 8. EIS measurements on CP Ti substrate: (a) Nyquist plot, (b) Bode plot; on TiAl6V4 substrate: (c) Nyquist plot, (d) Bode plot; TiC/a:C coated Ti: (e) Nyquist plot, (f) Bode plot; TiC/a:C coated TiAl6V4: (g) Nyquist plot, (h) Bode plot; and TiC/a:C coated sandblasted TiAl6V4: (i) Nyquist plot, (j) Bode plot 
the work of Wang et al. [7] in the case of the TiN and TiCN coatings) than for pure substrates. The total impedance values of TiC/a: $\mathrm{C}$ coatings are also smaller by almost one order of magnitude compared to that of for bare implant materials (Figure 8f, h, and j).

The evaluation of EIS data was implemented in electrical equivalent circuit (EEC) models (Figure 9) [2]. The most common form of circuit model is a two-time-constant model with resistances and capacitances related to each of the coating and the substrate. To evaluate the impedance data of samples, an appropriate equivalent circuit is to be used to simulate the processes occurring at electrode interfaces. The best goodness of fitting was obtained for substrate materials using two serial connected $(R \mid \mathrm{CPE})$ sub-circuits, where CPE is constant phase element. In the left side of Figure $9, R_{\mathrm{S}}$ is an uncompensated solution resistance between the coating and the reference electrode. The impedance of a phase element is defined as $Z_{\mathrm{CPE}}=$ $1 /\left[Q(j \omega)^{n}\right]$, where the exponent $n$ of the CPE is related to the non-equilibrium current distribution due to the surface roughness and surface defects. The CPE (which represents deviation from the true capacitor behavior) is used here instead of an ideal double layer capacitance. The high frequency time constant $\left(R_{\text {coat }} \mathrm{CPE}_{\text {coat }}\right)$ is related to the oxide layer formed on the surface of implant during measurements. $R_{\mathrm{ct}} \mathrm{CPE}_{\mathrm{ct}}$ is used to describe the charge transfer process at the substrate/oxide layer interface, where $R_{\mathrm{ct}}$ represents the charge transfer resistance and $\mathrm{CPE}_{\mathrm{ct}}$ is the double layer capacitance of the material. In the case of TiC/a:C coated substrates, using three serial connected $(R \mid \mathrm{CPE})$ sub-circuits provided the best quality of fits. In the right side of Figure 9, the high frequency time constant ( $\left.R_{\text {coat }} \mathrm{CPE}_{\text {coat }}\right)$ is refer to the contribution of TiC/a:C films to impedance response, while the low frequency time constant $R_{\mathrm{ct}} \mathrm{CPE}_{\mathrm{ct}}$ is used to describe the charge transfer processes at the substrate/coating interface. $R_{\mathrm{ct}}$ is the charge transfer resistance, and $\mathrm{CPE}_{\mathrm{ct}}$ is the double layer capacitance of the substrate. The third serial connected sub-circuit $\left(R_{\mathrm{CP}} \mathrm{CPE}_{\mathrm{CP}}\right)$ in this case refers to the corrosion products generated in the coating during immersion time.

3.3.3. ICP-OES measurement. In order to examine the metal contents in the SBF solution, the electrochemical tests were followed by the ICP-OES measurement. The results obtained from ICP-OES are illustrated in Table 3. However, the presence of $\mathrm{V}$ is detectable in each case, the $\mathrm{Al}$ and $\mathrm{Ti}$ ions have been detained by the TiC/a:C thin film coated s.b. TiAl6V4. The other ions shown in Table 3 originate from other contaminants and also the components of the SBF solution (Table 1).

3.3.4. Discussion. The main findings of this study are that the $\mathrm{TiC} / \mathrm{a}: \mathrm{C}$ protective coating on different substrates, while providing a high hardness to the surface, is also susceptible to electrochemical processes. Generally, it can be stated that $j_{\text {corr. }}$ is a value inversely proportional to polarization resistance $\left(R_{\mathrm{p}}\right)$. From the evaluation of potentiodynamic curves, it can be observed that the corrosion potential ( $\left.E_{\text {corr. }}\right)$ of bare substrate materials are more positive than that of $\mathrm{TiC} / \mathrm{a}: \mathrm{C}$ thin films in all cases (Figure 10a) and the corrosion current density values of $\mathrm{TiC} / \mathrm{a}: \mathrm{C}$ coated substrates are higher by one order of magnitude. The corrosion current density values of bare implant materials are low; they range between 1 and $3.5 \mu \mathrm{A}$, and they hardly change over time (see enlargement of Figure 10b). It can be stated that the bare materials are stable over a long-term period; however, after 10 days of immersion time, their $j_{\text {corr. }}$ values started to increase with decreasing their $R_{\mathrm{p}}$ values while the TiC/a:C coated s.b. TiAl6V4 shows much better results in both cases. On the other hand, the TiC/a:C thin films have higher $j_{\text {corr. }}$ values in all cases and they show a little increasing tendency with time after around 5 days of immersion time except for TiC/a:C coated s.b. TiAl6V4 alloy. The $j_{\text {corr. }}$ value of sample surface-treated by sandblasting before TiC/a:C nanocomposite coating deposition showed slight decreasing tendency over time, and it has the lowest value compared to the other TiC/a:C layers. This phenomenon proves that roughening the surface by sandblasting can enhance the corrosion resistance because the surface roughness influences the corrosion rate. As a consequence, the TiC/a:C coated sandblasted TiAl6V4 alloy possess the highest polarization resistances over time while the lowest resistances belong to $\mathrm{TiC} / \mathrm{a}: \mathrm{C}$ coated polished wafers (Figure 10c). Secondly, it was observed from the ICP-OES results that the TiC/a:C coated sandblasted TiAl6V4 alloy prevents the dissolution of both $\mathrm{Ti}$ and $\mathrm{Al}$. Overall, the TiC/a:C thin film - mainly on roughened surface - has suitable

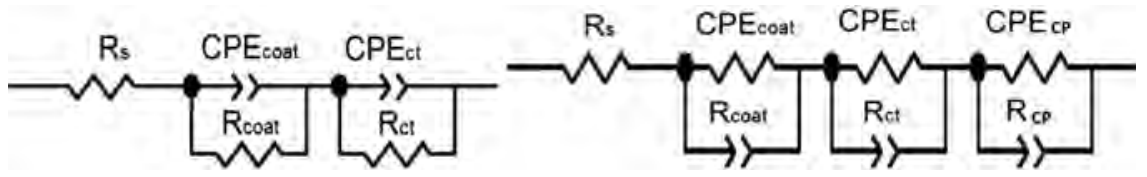

Figure 9. Proposed electrical equivalent circuit (EEC) models used to simulate the measured data for implant materials (two-time-constant model to the left) and TiC/a:C nanocomposite coated metallic implants (three-time-constant model to the right)

Table 3. Results of the ICP-OES measurements are shown. The concentrations of ions in the SBF solution were determined in ppb and ppm.

\begin{tabular}{|c|c|c|c|c|c|}
\hline$\mu \mathrm{g} / \mathrm{L}(\mathrm{ppb}) /$ Samples & TiC/a:C coated $\mathrm{Ti}$ & TiC/a:C coated TiAl6V4 & TiC/a:C coated s.b.TiAl6V4 & Uncoated $\mathrm{Ti}$ & Uncoated TiAl6V4 \\
\hline $\mathrm{Ti}$ & $3.0 \pm 0.15$ & $2.0 \pm 0.1$ & $<$ d.1. ${ }^{*}$ & $<$ d. $^{*}{ }^{*}$ & $<$ d. $^{*}{ }^{*}$ \\
\hline $\mathrm{Al}$ & - & $<$ d.1. & $<\mathrm{d}$. $^{*}$ & - & $3.0 \pm 0.15$ \\
\hline $\mathrm{V}$ & - & $1.0 \pm 0.1$ & $2.0 \pm 0.1$ & - & $2.0 \pm 0.1$ \\
\hline $\mathrm{Ag}$ & $2.0 \pm 0.1$ & $<$ d.1. ${ }^{*}$ & $11 \pm 1$ & $3.0 \pm 0.15$ & $4.0 \pm 0.2$ \\
\hline $\mathrm{Mn}$ & $2.0 \pm 0.1$ & $1.0 \pm 0.1$ & $7.0 \pm 0.4$ & $7.0 \pm 0.4$ & $9.0 \pm 0.5$ \\
\hline $\mathrm{Cu}$ & $35 \pm 2$ & $27 \pm 1$ & $103 \pm 5$ & $119 \pm 6$ & $155 \pm 8$ \\
\hline $\mathrm{Fe}$ & $1.0 \pm 0.1$ & $3.0 \pm 0.2$ & $1.0 \pm 0.1$ & $14 \pm 1$ & $6.0 \pm 0.3$ \\
\hline $\mathrm{Ni}$ & $62 \pm 3$ & $61 \pm 3$ & $553 \pm 28$ & $343 \pm 17$ & $545 \pm 27$ \\
\hline $\mathrm{Sr}$ & $18 \pm 1$ & $16 \pm 1$ & $17 \pm 1$ & $552 \pm 28$ & $667 \pm 33$ \\
\hline $\mathrm{Zn}$ & $13 \pm 1$ & $6.0 \pm 0.3$ & $13 \pm 0.7$ & $<$ d.1. ${ }^{*}$ & $40 \pm 2$ \\
\hline$\overline{\mathrm{mg} / \mathrm{L}(\mathrm{ppm}) / \text { Samples }}$ & "1" & $" 2 "$ & "3" & $" 4 "$ & "5" \\
\hline $\bar{K}$ & $296 \pm 6$ & $353 \pm 7$ & $267 \pm 5$ & $290 \pm 6$ & $252 \pm 5$ \\
\hline $\mathrm{P}$ & $47 \pm 1$ & $52 \pm 1$ & $43 \pm 1$ & $48 \pm 1$ & $39 \pm 1$ \\
\hline S & $22 \pm 0.4$ & $23 \pm 0.5$ & $19 \pm 0.4$ & $26 \pm 1$ & $19 \pm 0.4$ \\
\hline $\mathrm{Mg}$ & $34 \pm 1$ & $37 \pm 1$ & $31 \pm 1$ & $37 \pm 1$ & $31 \pm 1$ \\
\hline $\mathrm{Ca}$ & $73 \pm 1$ & $77 \pm 2$ & $69 \pm 1$ & $51 \pm 1$ & $39 \pm 1$ \\
\hline
\end{tabular}



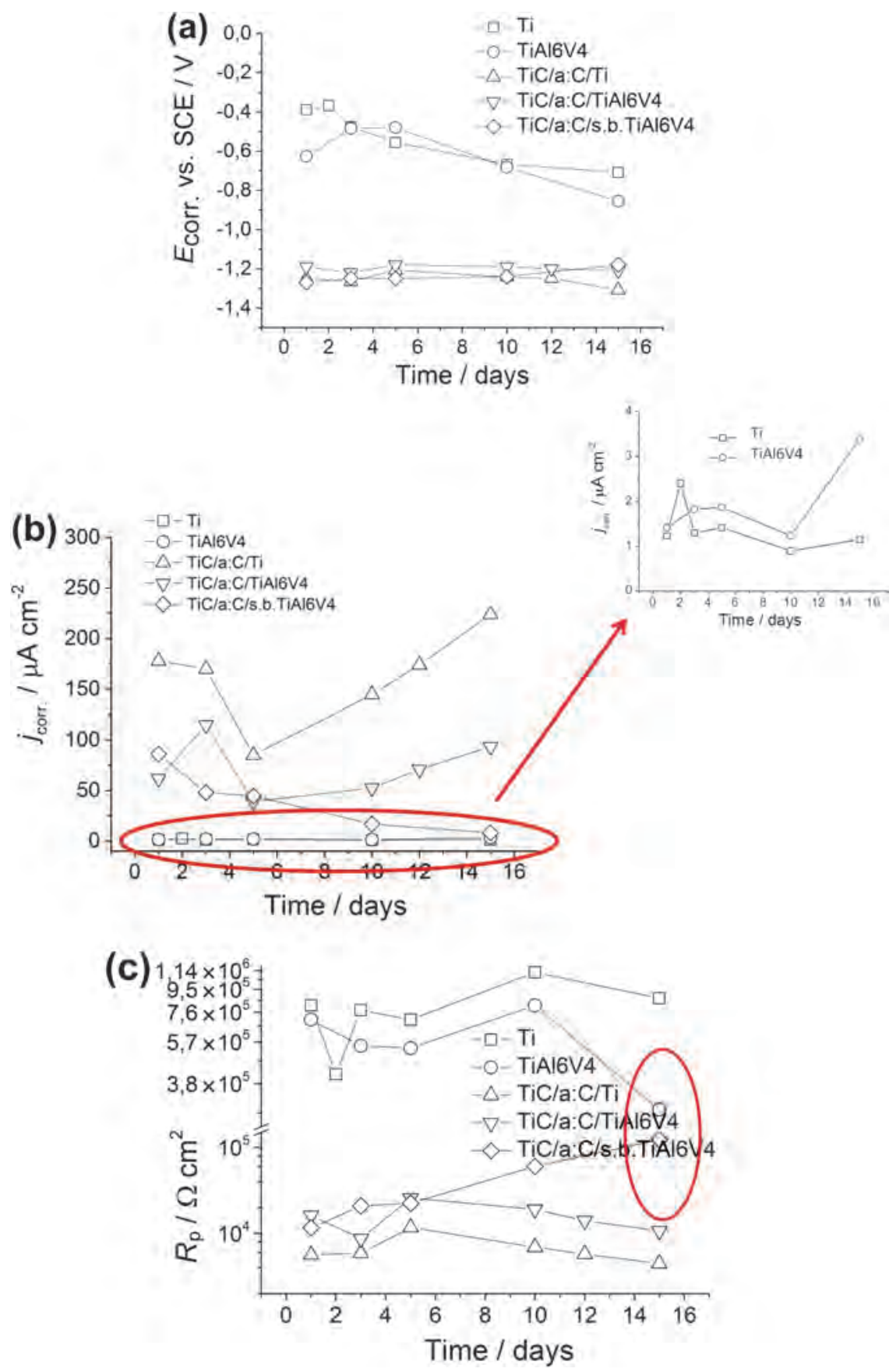

Figure 10. $E_{\text {corr. }}(\mathrm{a}), j_{\text {corr. }}(\mathrm{b})$, and $R_{\mathrm{p}}$ (c) values of TiC/a:C coated and uncoated implant materials derived from potentiodynamic curves in Figure 7

electrochemical characteristics for further consideration and assessment as a protective coating.

\section{Conclusion}

The aim of this study was to create a protective TiC/a:C nanocomposite coating as surface thin film to the most commonly used $\mathrm{Ti}$ and TiAl6V4 implant materials to improve their corrosion and mechanical properties. In conclusion, this protective coating on Ti and TiAl6V4 substrates is successfully deposited by DC magnetron sputtering at room temperature. It can be stated that $j_{\text {corr. }}$ is a value inversely proportional to polarization resistance $\left(R_{\mathrm{p}}\right)$. The $j_{\text {corr. }}$ values of the bare materials started to increase with decreasing their $R_{\mathrm{p}}$ values while the TiC/a:C coated s.b. TiAl6V4 shows reverse results in both cases after 10 days of immersion time. In the case of the TiC/a:C coated s.b. TiAl6V4 alloy, after 10 days of immersion time, its $j_{\text {corr. }}$ value started to decrease with increasing its $R_{\mathrm{p}}$ value. This result proves that roughening the surface by sandblasting can enhance the corrosion resistance, and the $\mathrm{TiC} / \mathrm{a}: \mathrm{C}$ thin film as a protective coating to implant devices can control the metal ion release as it was proved by the ICP-OES measurements. It was also found that the hardness of the bare implant materials was improved by four orders of magnitude with the $\mathrm{TiC} / \mathrm{a}: \mathrm{C}$ nanocomposite coating besides a moderate elastic modulus value. Overall, the main conclusion of this article is that a ceramic TiC/a:C thin film with $20 \mathrm{at} \% \mathrm{a}: \mathrm{C}$ and $\sim 38$ at $\%$ Ti contents would be a suitable choice for a protective nanocomposite coating.

Acknowledgments. N. Oláh thanks Young Research Fellowship of Hungarian Academy of Sciences (FIKU) for the support. N. Oláh also thanks L. Illés for the SEM measurements and T. Csanádi for the mechanical measurements. 
Open Access. This is an open-access article distributed under the terms of the Creative Commons AttributionNonCommercial 4.0 International License (https:// creativecommons.org/licenses/by-nc/4.0/), which permits unrestricted use, distribution, and reproduction in any medium for non-commercial purposes, provided the original author and source are credited, a link to the CC License is provided, and changes - if any - are indicated.

\section{References}

1. Santos, P. F; Niinomi, M; Cho, K. Nakai, M. Liu, H.; Ohtsu, N.; Hirano, M.; Ikeda, M.; Narushima, T. Acta Biomater. 2015, 26, 366-376.

2. Milošev, I.; Metikoš-Huković, M.; Strehblow, H. H. Biomaterials 2000, 21, 2103-2113.

3. Matykina, E.; Arrabal, R.; Valiev, R. Z.; Molina-Aldareguia, J. M.; Belov, P.; Sabirov, I. Electrochim. Acta 2015, 176, 1221-1232.

4. Oliveira, N. T. C.; Guastaldi, A. C. Acta Biomater. 2009, 5, 399-405.

5. Gepreel, M. A.-H.; Niinomi, M. J. Mech. Behav. Biomed. Mater. 2013, 20, 407-415.

6. Thair, L.; Mudali, U. K.; Rajagopalan, S.; Asokamani, R.; Raj, B. Corros. Sci. 2003, 45, 1951-1967.

7. Wang, Q.; Zhou, F.; Zhou, Z.; Li, L. K.-Y.; Yan, J. Surf. Coat. Technol. 2014, 253, 199-204.

8. Simka, W. Electrochim. Acta 2011, 56, 9831-9837.

9. Souto, R. M.; Laz, M. M.; Reis, R. L. Biomaterials 2003, 24, 4213-4221.

10. Dalmau, A; Pina, V. G.; Devesa, F.; Amigó, V.; Muñoz, A. I. Electrochim. Acta 2013, 95, 102-111.

11. Martín-Cameán, A.; Jos, Á.; Mellado-García, P.; Iglesias-Linares, A.; Solano, E.; Cameán, A. M. Environ. Toxicol. Phar. 2015, 40, 86-113.

12. Santos, P. F.; Niinomi, M.; Liu, H.; Cho, K.; Nakai, M.; Itoh, Y.; Narushima, T.; Ikeda, M. J. Mech. Behav. Biomed. Mater. 2016, 59, 497-507. 13. Correa, D. R. N.; Kuroda, P. A. B.; Grandini, C. R.; Rocha, L. A.; Oliveira, F. G. M.; Alves, A. C.; Toptan, F. Mater. Lett. 2016, 179, 118-121.

14. Wang, X.; Zhang, L.; Guo, Z.; Jiang, Y.; Tao, X.; Liu, L. J. Mech. Behav. Biomed. Mater. 2016, 62, 310-318.

15. Zhang, L.; Wang, K.; Xu, L.; Xiao, S.; Chen, Y. Trans. Nonferrous Met. Soc. China 2015, 25, 2214-2220.

16. Khan, M. A.; Williams, R. L.; Williams, D. F. Biomaterials 1999, 20, 631-637.
17. Çomaklı, O.; Yazıcı, M.; Yetim, T.; Yetim, A. F.; Çelik, A. Surf. Coat. Tech. 2016, 285, 298- 303 .

18. Jinlong, L.; Tongxiang, L.; Chen, W.; Limin, D. Mater. Sci. Eng: C 2016, 63, 192-197.

19. Aun, D. P.; Houmard, M.; Mermoux, M.; Latu-Romain, L.; Joud, J.-C.; Berthomé, G.; Buono, V. T. L. Appl. Surf. Sci. 2016, 375, 42-49.

20. Li, D. G.; Wang, J. D.; Chen, D. R.; Liang, P. Ultrason. Sonochem. 2016, $29,48-54$.

21. Browne, M.; Gregson, P. J. Biomaterials 2000, 21, 385-392.

22. Oláh, N.; Fogarassy, Z.; Furkó, M.; Balázsi, C.; Balázsi, K. Ceram. Int. 2015, 41, 5863-5871.

23 Shanaghi, A.; Chu, P. K.; SabourRouhaghdam, A. R.; Xu, R.; Hu, T. Surf. Coat. Tech. 2013, 229, 151-155.

24. Chenghao, L.; Li'nan, J.; Chuanjun, Y.; Naibao, H. Metal. Mat. Eng. 2015, 44, 0781-0785.

25. Cvijović-Alagić, I.; Cvijović, Z.; Mitrović, S.; Panić, V.; Rakin, M. Corros. Sci. 2011, 53, 796-808.

26. Wu, Q.; Li, W.; Zhong, N. Corros. Sci. 2011, 53, 4258-4264.

27. Oláh, N.; Fogarassy, Z.; Sulyok, A.; Szívós, J.; Csanádi, T.; Balázsi, K. Ceram. Int. 2016, 42, 12215-12220.

28. Ignaszak, A.; Song, C.; Zhu, W.; Zhang, J.; Bauer, A.; Baker, R.; Neburchilov, V.; Ye, S.; Campbell, S. Electrochim. Acta. 2012, 69, 397-405.

29. Dang, H. P.; Luc, Q. H.; Le, V. H.; Le, T. J. Alloy. Compd. 2016, 687, 1012-1020.

30. Bociaga, D.; Kaminska, M.; Sobczyk-Guzenda, A.; Jastrzebski, K.; Swiatek, L.; Olejnik, A. Diam. Relat. Mater. 2016, 67, 41-50.

31. Wang, C.; Yang, Y.; Chung, Y.-W.; Zhang, Y.; Ouyang, S.; Xiao, Z.; Song,

K.; Li, P. Ceram. Int. 2016, 42, 6342-6346.

32. Li, J.; Zhang, H.; Fan, A.; Tang, B. Surf. Coat. Tech. 2016, 294, 30-35.

33. Musil, J.; Vlček, J. Surf. Coat. Tech. 2001, 142, 557-566.

34. Oláh, N.; Veres, M.; Sulyok, A.; Menyhárd, M.; Gubicza, J.; Balázsi, K. J. Eur. Ceram. Soc. 2014, 34, 3421-3425.

35. Oláh, N.; Fogarassy, Z.; Sulyok, A.; Veres, M.; Kaptay, G.; Balázsi, K. Surf. Coat. Tech. 2016, 302, 410-419.

36. Oliver, W. C.; Pharr, G. M. J. Mater. Res. 1992, 7, 1564-1583.

37. Talos, F.; Senilă, M.; Frentiu, T.; Simon, S. Corros. Sci. 2013, 72, 41-46.

38. Sedira, S.; Achour, S.; Avci, A.; Eskizeybek, V. Appl. Surf. Sci. 2014, 295, 81-85.

39. Marques, M. R. C.; Loebenberg, R.; Almukainzi, M. Dissolut. Technol. 011, 18, 15-28.

40. Swaminathan, V.; Zeng, H.; Lawrynowicz, D.; Zhang, Z.; Gilbert, J. L. Electrochim. Acta 2012, 59, 387-397.

41. Sivakumar, B.; Singh, R.; Pathak, L. C. Mater. Sci. Eng: C 2015, 48, 243-255.

42. Velasquez, S. C.; Galindo, R. E.; Oliveira, J. C.; Cavaleiro, A.; Carvalho, S. Surf. Coat. Tech. 2013, 222, 104-111. 